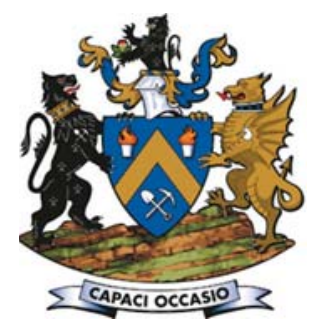

\title{
Application of finite element method and artificial neural networks to predict the rolling force in hot rolling of $\mathrm{Mg}$ alloy plates
}

\author{
by Z.Y. Guo*t, J.N. Sun*t, and F.S. Du*t
}

\section{Synopsis}

A computational model combining a finite element method (FEM) with an artificial neural network (ANN) was developed to predict the rolling force in the hot rolling of $\mathrm{Mg}$ alloy plates. FEM results were compared with experimental data to verify the accuracy of the finite element model. Numerous thermomechanical finite element simulations were carried out to obtain a database for training and validation of the network. The input variables were initial thickness, thickness reduction, initial temperature of the plate, friction coefficient in the contact area, and rolling speed. The optimal ANN model was obtained after repeated training and studying of the samples. The trained network gave satisfactory results when comparing the ANN predictions and FEM simulation results. A comprehensive validation of the prediction model is presented. The resulting ANN model was found to be suitable for online control and rolling schedule optimization in the hot rolling process of $\mathrm{Mg}$ alloy plate.

\section{Keywords}

Mg alloy, finite element method, artificial neural network, hot rolling, rolling force.

\begin{abstract}
Introduction
Magnesium alloys have low density and high specific strength, high specific stiffness, and many other advantages (Mordike et al., 2001). With the increased consciousness of energy saving and environmental protection, $\mathrm{Mg}$ alloys are becoming widely recognized as the candidates to replace steel and aluminium alloys in many fields, such as in vehicles and the electronics industry. $\mathrm{Mg}$ alloys are thus becoming known as new 'green' engineering materials in the 21st century (Hosokawa et al., 2003). However, Mg and its alloys have very poor ductility at room temperature due to their hexagonal close-packed (HCP) crystal structure, and rolled $\mathrm{Mg}$ alloy sheets show a strong basal texture, therefore limiting their application (Thirumurugan et al., 2011). Much research has been done to study the deformation mechanism of $\mathrm{Mg}$ alloys, with the aim of improving the ductility and strength (Li et al., 2013; Choi et al., 2007; Choi et al., 2009). It has been shown that the microstructures, texture evolution, and mechanical properties of $\mathrm{Mg}$ alloys are highly reliant on their primary deformation process, such as differential-speed rolling (Lee et al., 2010), cross-rolling (Kang et al., 2008),
\end{abstract}

accumulative roll-bonding (Saito et al., 1999), and asymmetrical rolling (Gao et al., 2002). The microstructures have been studied extensively and most of the technology still remains at the research stage. In order to expand the application of $\mathrm{Mg}$ alloy products, production of rolled $\mathrm{Mg}$ alloy sheets must be commercialized.

The prediction model for rolling force is the crucial part of the computer-controlled system in the hot rolling of $\mathrm{Mg}$ alloys. Rolling force prediction methods include mathematical models, finite element models, intelligent methods (e.g. artificial neural networks, or ANNs), and a combination of ANNs and mathematical models. Using the mathematical model method to calculate rolling force is simple but has low precision. Using the finite element method (FEM) to simulate the rolling process decreases assumptions, but is timeconsuming and EMS (expanded memory system) memory-intensive (Sun et al., 2009). The intelligent method includes ANNs, genetic algorithms, and fish-net algorithms.

Recently, a computational model combining a FEM with an ANN was used for various metallurgical problems (Esmailzadeh et al., 2012; Shabani et al., 2012) and prediction of mechanical properties (Shabani et al, 2011). ANN-FEM was used to predict residual stresses and the optimal cutting conditions during hard turning of bearing steel (Umbrello et al., 2007), springback prediction for incremental sheet forming (Han et al., 2013), and other aspects of metal forming processes (Kim et al., 2000). However, to the best of the authors' knowledge, the computational method has rarely been used to

* National Engineering Research Center for Equipment and Technology of Cold Strip Rolling, Qinhuangdao, China.

$\uparrow$ School of Mechanical Engineering, Yanshan University, China.

(C) The Southern African Institute of Mining and Metallurgy, 2016. ISSN 2225-6253. Paper received Jun. 2014; revised paper received Jul. 2015. 


\section{Application of finite element method and artificial neural networks}

predict the rolling force in the hot rolling of $\mathrm{Mg}$ alloy plates. In the process of real production, the predictions of conventional models have relatively large errors in the rolling force. For the purpose of satisfying both computation speed and calculation precision in practical production, a computational model that combines FEM with ANN was developed to predict the rolling force. The commercial finite element software MSC.Marc was used to simulate the $\mathrm{Mg}$ alloy rolling process; then Matlab Toolbox was used to train a back-propagation neural network by applying the input variables and FEM simulation results. This new computational method makes full use of the advantages of the FEM and ANN. The resulting model can predict the rolling force of $\mathrm{Mg}$ alloy plate quickly and accurately, and can be used for the optimization of the $\mathrm{Mg}$ alloy rolling schedule and online control of the rolling process.

\section{Finite element modelling}

In this $\mathrm{Mg}$ alloy hot rolling process, the plate is more than $600 \mathrm{~mm}$ wide, so the modelling can be regarded as a planestrain problem, which can save calculation time without losing too much accuracy. Thus, a three-dimensional problem can be reasonably described by a two-dimensional problem. Only half of the plate was modelled due to the symmetric nature of its rolling situation, as shown in Figure 1. The plate was taken to be $100 \mathrm{~mm}$ long for the purpose of reducing analysis time. The rolling was performed with a work roll temperature of $160^{\circ} \mathrm{C}$ (Zhang et al., 2010) and a work roll diameter of $425 \mathrm{~mm}$ for all finite element models.

The steel work roll stiffness is very high relative to $\mathrm{Mg}$ alloys. For simplification, it can be assumed that the work roll is a rigid-thermal contact body and the rolling piece is a thermoplastic contact body. Thermomechanically coupled FE models of the $\mathrm{Mg}$ alloy plate hot rolling process were developed under various rolling conditions. An arbitrary Lagrangian-Eulerian (ALE) method was employed as a formulation technique through the use of the commercial general-purpose FE program MSC.Marc. The flow stress was coupled to the rolling temperature, strain rate, and strain. The boundary condition type was 'plastic - heat generation'.

The temperature of the plate will increase because of the heat of deformation. The governing partial differential equation for heat conduction is given by (Kobayashi et al., 2009):

$$
\rho c_{\rho} \frac{\partial T}{\partial t}=\frac{\partial}{\partial x}\left(k \frac{\partial T}{\partial x}\right)+\frac{\partial}{\partial y}\left(k \frac{\partial T}{\partial y}\right)+\frac{\partial}{\partial z}\left(k \frac{\partial T}{\partial z}\right)+q_{v}
$$

where $\rho$ is the density of the plate $\left(\mathrm{kg}^{-3} \mathrm{~m}^{-3}\right), c_{\rho}$ is the specific heat of the plate $\left(\mathrm{J} . \mathrm{kg}^{-1} \cdot \mathrm{K}^{-1}\right), k$ is the thermal conductivity of the rolled plate $\left(\mathrm{W} \cdot \mathrm{m}^{-1} \cdot \mathrm{K}^{-1}\right), q_{v}$ represents the volumetric rate of heat generation originated from the deformation $\left(\mathrm{J} \cdot \mathrm{m}^{-3} \cdot \mathrm{s}^{-1}\right)$, $t$ represents time $(S), T$ is the temperature of the plate $(\mathrm{K})$, and the plate's location is described by using $\mathrm{x}, \mathrm{y}, \mathrm{z}$ coordinates. $q_{v}$ is calculated using the equation (Freshwater et al., 1996):

$$
q_{v}=\psi \sigma \dot{\varepsilon} t
$$

where $\psi$ is the efficiency of conversion of plastic plate into heat (assumed to be 0.9, which is considered reasonable for $\mathrm{Mg}$ alloys), $\sigma$ is the true stress of the plate (Pa), and $\dot{\varepsilon}$ is the true strain of the plate (Figure 2).

The friction stress on the contact surface between the plate and the work roll must be considered, as given by (Shahani et al., 2009):

$$
\tau=\mu p
$$

where $\tau$ is the critical shear stress (Pa), $\mu$ is the coefficient of friction, and $p$ is the contact pressure $(\mathrm{Pa})$. Interfacial friction for the contact area is proportional to the normal force. The coefficient of friction has a wide range due to modelling assumptions and the range of tested rolling conditions.

The plate material was a commercial Mg alloy, AZ31B, which has wide industrial applications. Parameters such as deformation resistance, elastic modulus, thermal

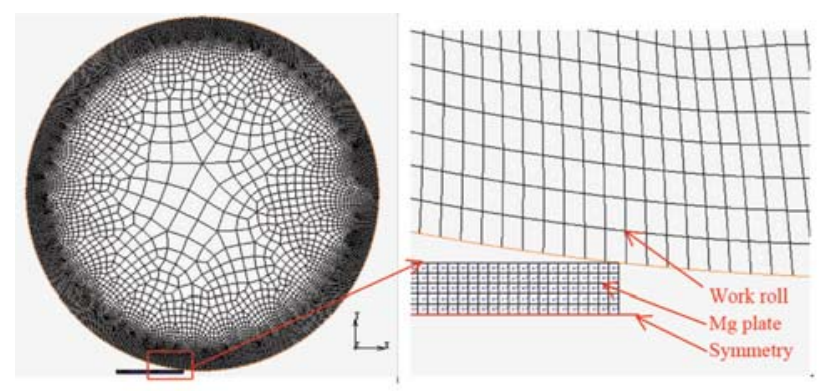

Figure 1-Finite element analysis model
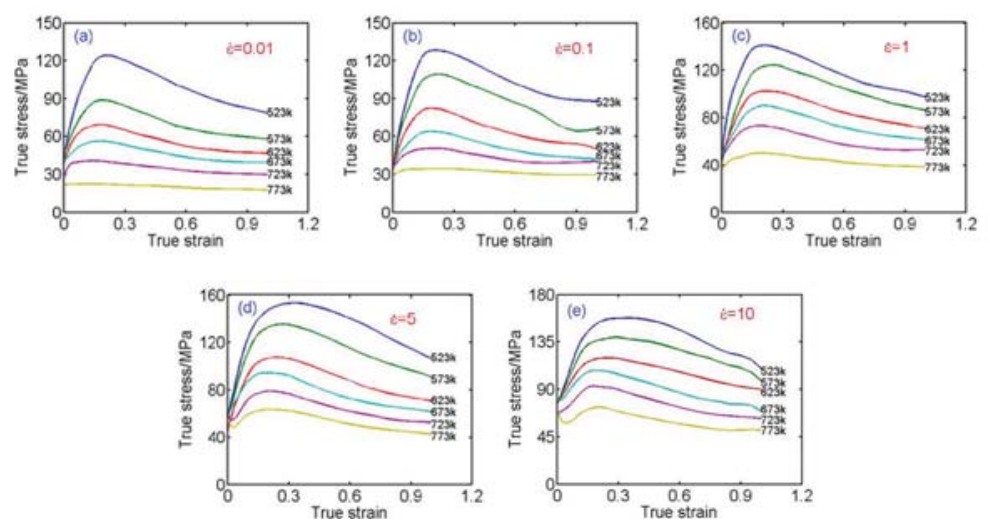

Figure 2-True stress-strain curves of AZ31B as a function of temperature and strain rate 


\section{Application of finite element method and artificial neural networks}

conductivity, and heat capacity vary greatly at different temperatures for this alloy. The true stress-strain curves of AZ31B (Sun et al., 2013) as a function of rolling temperature and strain rate are shown in Figure 2. The thermo-physical properties used for AZ31B are shown in Figure 3, and Table I summarizes those of the $40 \mathrm{Cr}$ work roll.

\section{Calculation and experimental verification}

The experimental rolling conditions used are summarized in Table II. A comparison between the FEM calculated roll force results and experimental data from a hot strip rolled 1725 $\mathrm{mm}$ wide $\mathrm{Mg}$ alloy plate is presented in Table III. As observed, the maximum relative error is $8.6 \%$. The FEM results are shown to be in good agreement with the experimental data. The FEM predicted values can therefore be used as a substitution to generate the training data for neural network modelling.

\section{Prediction of rolling force based on ANN}

The predicted values of rolling force by the FE model for an industrial rolling process are encouraging. However, the FE method needs repeated setting up because of the different $\mathrm{Mg}$ alloy plate parameters and rolling conditions, and the calculation time is long. It is therefore not suitable for online prediction. ANNs are bionic techniques that imitate the basic principles of brain functions, and have undergone rapid development in the past decade. Utilizing the nonlinear reflecting and association learning abilities of the backpropagation neural network technique (BPNN), the hot plate rolling force of $\mathrm{Mg}$ alloys can be predicted relatively accurately and rapidly.

\section{Artificial neural network model}

The hot rolling of $\mathrm{Mg}$ alloys is a complicated nonlinear problem and many factors influence the rolling force. Omitting the less-important parameters such as work roll diameter, which changes little during the rolling process, benefits the development of the model. The selected independent input variables are initial thickness of the plate,

\begin{tabular}{|c|c|c|}
\hline \multicolumn{3}{|l|}{ Table I } \\
\hline \multicolumn{3}{|c|}{$\begin{array}{l}\text { Thermo-physical properties used for the } 40 \mathrm{Cr} \text { steel } \\
\text { work roll }\end{array}$} \\
\hline Thermal conductivity, W. $\mathrm{m}^{-1} \cdot \mathrm{K}^{-1}$ & Density, kg.m-3 & Poisson's ratio \\
\hline 15 & 1780 & 0.35 \\
\hline
\end{tabular}

percentage thickness reduction, initial plate temperature, friction coefficient in the contact area, and rolling speed. The output parameter is rolling force.

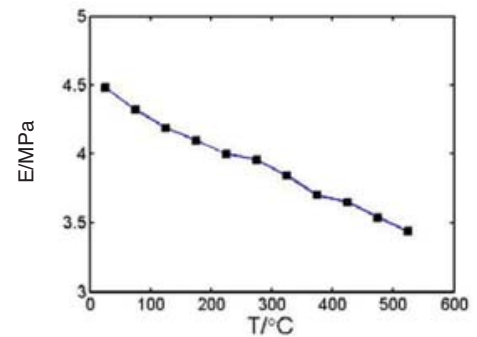

Figure 3a-Elastic modulus of AZ31B at different temperatures

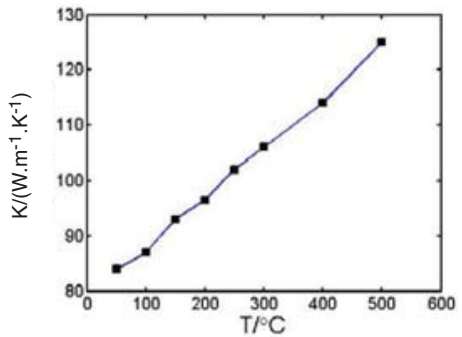

Figure $3 b-$ Thermal conductivity of AZ31B at different temperatures

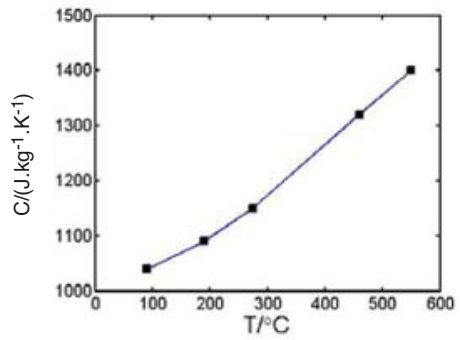

Figure 3c-Heat capacity of AZ31B at different temperatures

Table III

Results and comparisons of rolling force

\begin{tabular}{|l|c|c|c|}
\hline Sample no. & $\begin{array}{c}\text { Roll force (MN) } \\
\text { experimental data }\end{array}$ & $\begin{array}{c}\text { Roll force (MN) } \\
\text { FEM results }\end{array}$ & $\begin{array}{c}\text { Relative error } \\
\text { (\%) }\end{array}$ \\
\hline 1 & 5.05 & 5.01 & 0.8 \\
2 & 5.02 & 5.45 & -8.6 \\
3 & 5.53 & 5.60 & -1.3 \\
4 & 5.58 & 5.78 & -3.5 \\
5 & 5.77 & 5.62 & 0.3 \\
\hline
\end{tabular}

Table II

Conditions of hot rolling experiments employed for the simulation

\begin{tabular}{|c|c|c|c|c|c|c|}
\hline Sample no. & Width (mm) & Incoming thickness (mm) & Outgoing thickness (mm) & Roll speed (m/s) & Temperature $\left({ }^{\circ} \mathrm{C}\right)$ & Friction coefficient $\mu$ \\
\hline 1 & 700 & 11.50 & 5.15 & \multirow{5}{*}{0.6} & \multirow{5}{*}{325} & \multirow{5}{*}{0.2} \\
\hline 2 & 680 & 10.50 & 4.60 & & & \\
\hline 3 & 700 & 10.00 & 3.68 & & & \\
\hline 4 & 700 & 9.00 & 3.40 & & & \\
\hline 5 & 750 & 8.00 & 3.20 & & & \\
\hline
\end{tabular}




\section{Application of finite element method and artificial neural networks}

The back-propagation algorithm is most commonly used to minimize the minimum mean square error by adjusting the weights and biases of the network. During training, $Q$ sets of input and output data are given to the neural network. An iterative algorithm adjusts the weights so that the outputs $\left(o_{k}\right)$ according to the input patterns will be as close as possible to their respective desired output patterns $\left(d_{k}\right)$. Considering a neural network with $K$ number of outputs, the mean square error (MSE) function to be minimized is (Kazan et al., 1994):

$$
\mathrm{MSE}=\frac{1}{Q \times K} \times \sum_{q=1}^{Q} \sum_{k=1}^{K} M\left[d_{k}(q)-o_{k}(q)\right]^{2}
$$

In this study, the input variables and the simulation results were used for training samples through varying the FE model parameters. In a factorial design, variable space is divided into levels between the lowest and the highest values. A three-level full factorial design creates $3^{n}$ training data samples, where $n$ is the number of variables. The constructed levels and factors of training samples are presented in Table IV. Hence, $3^{5}=243$ data samples were generated from the validated finite element model that was developed. Commercial $700 \mathrm{~mm}$ wide AZ31B Mg alloy plates were rolled. The training samples were divided into two subsets. The first subset of 195 randomly selected data was the training set used to adjust the network weights and biases. The second subset of 48 randomly selected data was the validation subset to monitor the training process in case the network overfitted the data.

In order to increase the training speed and to improve convergent behaviour, the data was normalized before developing the net. The following normalization equation processes input and target data from the original range to the range $\left[\begin{array}{ll}0 & 1\end{array}\right]$.

$$
x=\left(x_{k}-x_{\min }\right) /\left(x_{\max }-x_{\min }\right)
$$

where $x_{k}$ is the original data, and $x_{\min }$ is the minimum and $x_{\max }$ is the maximum value of $x$.

One of the most important tasks in ANN studies is to determine the transfer function and the training function. In this model, the tangential sigmoidal function was used in the hidden and output layers, which can improve the accuracy and efficiency of the ANN model. The L-M algorithm was selected as the training function as it is the best choice for moderate-sized neural networks and it has the fastest convergence rate (Hagan et al., 1994).

Table IV

Parameters of training samples

\begin{tabular}{|l|c|c|c|}
\hline \multirow{2}{*}{ In put variables } & \multicolumn{3}{|c|}{ Levels: } \\
\cline { 2 - 4 } & $\mathbf{1}$ & $\mathbf{2}$ & $\mathbf{3}$ \\
\hline Initial thickness $(\mathrm{mm})$ & 8 & 10 & 12 \\
Thickness reduction $(\%)$ & 30 & 50 & 70 \\
Temperature $\left({ }^{\circ} \mathrm{C}\right)$ & 250 & 300 & 350 \\
Friction coefficient & 0.15 & 0.2 & 0.25 \\
Rolling speed $(\mathrm{m} / \mathrm{s})$ & 0.4 & 1.2 & 2.0 \\
\hline
\end{tabular}

Another important task in ANN studies is to determine the optimal network architecture, which is related to the number of hidden layers and neurons in them. In this study, the best architecture of the network was obtained by trying different numbers of hidden layers and neurons. The trial started using one hidden layer with three neurons, and the performance of each network was checked by the correlation coefficient $(R)$. The neuron numbers in hidden layers have a direct effect on the ANN's nonlinear prediction ability. The goal is to maximize $\mathrm{R}$ to obtain a network with the best generalization. After training repeatedly, the optimal architecture of the ANN was constructed as 5-4-1, representing the number of inputs, neurons in the hidden layer, and outputs, respectively (Figure 4). The corresponding learning rate was 0.001 , the value of the training goal was $10^{-5}$, and the maximum training step was 2000 . The functions and architecture used in the resulting model are summarized in Table $\mathrm{V}$.

\section{Model analysis and prediction results}

By using the correlation coefficient $\mathrm{R}$, the performance of each network can be examined in terms of the relationship between the outputs of the network and the targets. Although the structure of the net is simple, the network outputs and the targets show a high level of correlation in Figure 5, with correlation coefficients of 0.9964 and 0.99278 for training data-sets and validation data-sets, respectively.

An early stopping method was used during the training to reduce the effect of overfitting. The error on the validation set would typically begin to rise when the network starts to overfit the data, and the training will stop when the

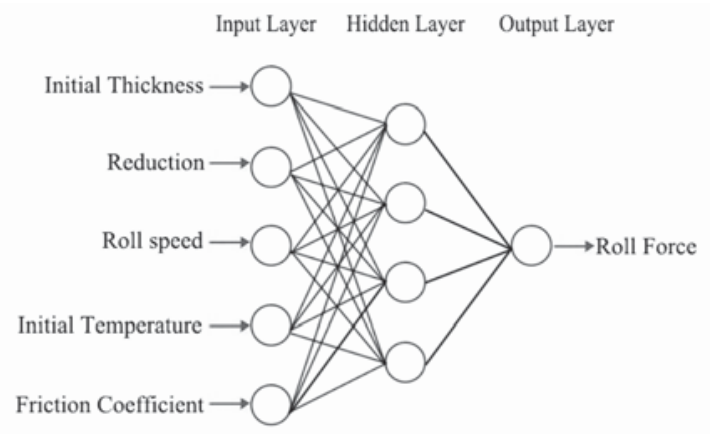

Figure 4-BP artificial neutral network model

\section{Table $\mathrm{V}$}

\begin{tabular}{|c|c|}
\hline Network & Feed-forward back-propagation network \\
\hline Transfer function & Tangential sigmoid \\
\hline Training function & Levenberg-Marquardt \\
\hline Learning function & $\begin{array}{l}\text { Gradient descent with momentum } \\
\text { weight and bias learning function }\end{array}$ \\
\hline Performance function & Mean squared error (MSE) \\
\hline Number of input layer unit & 5 \\
\hline Number of hidden layers & 1 \\
\hline Number of hidden layer units & 4 \\
\hline Number of output layer units & 1 \\
\hline
\end{tabular}

\section{The ANN architecture and functions}




\section{Application of finite element method and artificial neural networks}
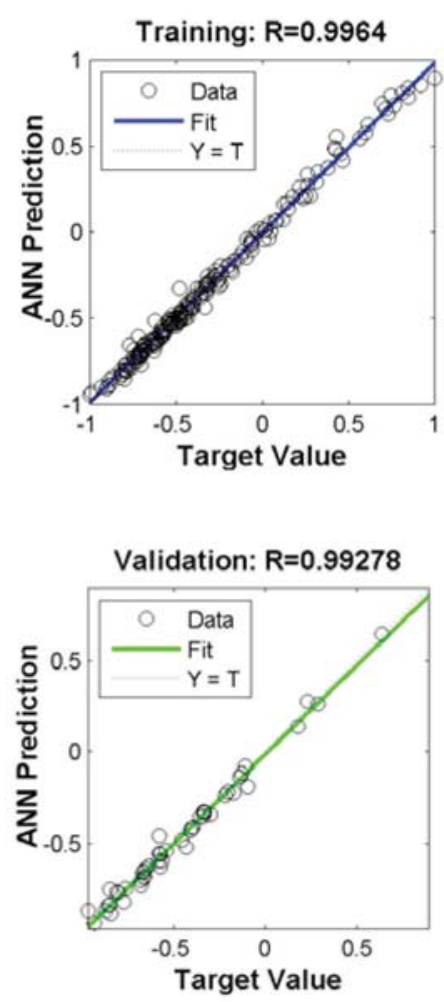

Figure 5a-Training performance of the proposed ANN model in prediction of roll force $(5 b)$ Validation performance of proposed ANN model in prediction of roll force

validation error increases for a specified number of iterations. Thus, the weights and biases at the minimum of the validation error would return (Bagheripoor et al., 2013). As can be seen from Figure 6, the minimum MSE of the validation set was as low as 0.0017 after 222 iterations, and no significant overfitting had occurred.

In order to test the prediction precision of the ANN model, $2^{5}=32$ testing samples were developed from the validated finite element model. The constructed levels and factors of the testing samples are presented in Table VI.

A comparison between ANN predictions and FEM simulation results is presented in Figure 7. The maximum relative error of the roll force prediction was $6.9 \%$, which implies that this method may be used in practical prediction. The resulting model is quite suitable for online control of a $\mathrm{Mg}$ alloy plate hot rolling process and can be utilized to design the rolling schedule for $\mathrm{Mg}$ alloy plates.

\section{Conclusions}

1. Thermomechanically coupled finite element models of the $\mathrm{Mg}$ alloy plate hot rolling process were established. The correlation between the FEM-calculated roll force and experimental data verified the reliability of the FE model

2. FE simulation results were taken as training and validation samples for the BP neural network. The optimum network was obtained by training repeatedly. The ANN predictions agree well with the testing samples,

Table VI

Parameters of testing samples

\begin{tabular}{|l|c|c|}
\hline \multirow{2}{*}{ Factors } & \multicolumn{2}{|c|}{ Levels } \\
\cline { 2 - 3 } & $\mathbf{1}$ & $\mathbf{2}$ \\
\hline Initial thickness $(\mathrm{mm})$ & 9 & 11 \\
Reduction $(\%)$ & 60 & 50 \\
Temperature $\left({ }^{\circ} \mathrm{C}\right)$ & 275 & 325 \\
Friction coefficient & 0.175 & 0.225 \\
Roll speed $(\mathrm{m} / \mathrm{s})$ & 0.8 & 1.6 \\
\hline
\end{tabular}

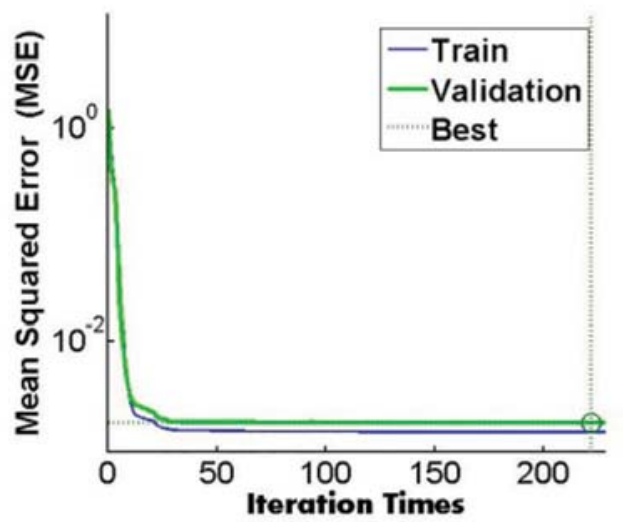

Figure 6-MSE of proposed ANN model in prediction of roll force

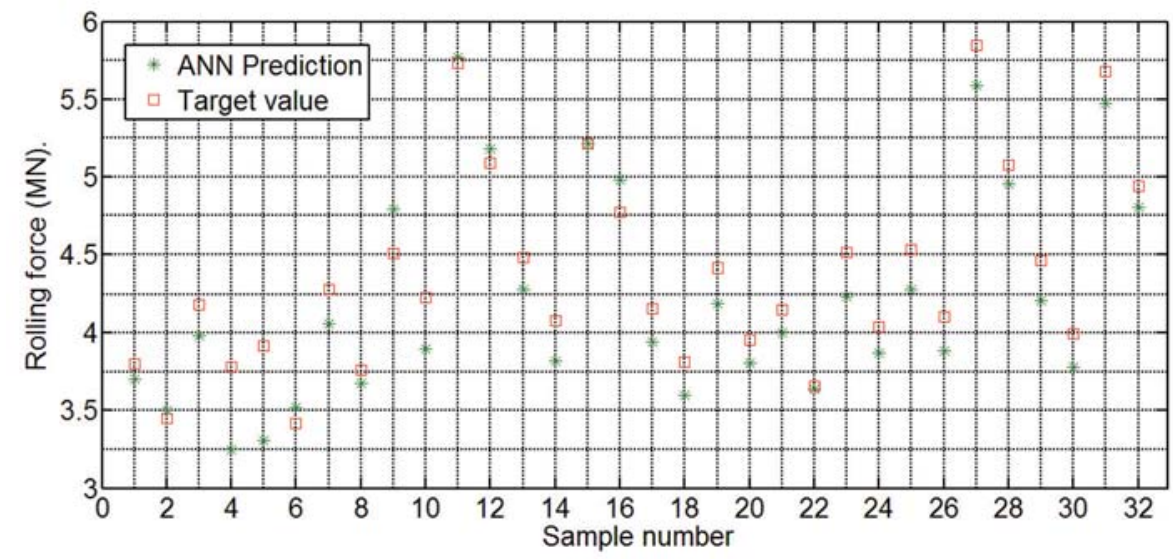

Figure 7-Comparison of ANN and FEM simulation results 


\section{Application of finite element method and artificial neural networks}

which indicates the ability of the model to predict Mg alloy rolling forces accurately and quickly in different hot rolling conditions. The resulting ANN model is suitable for the optimization of $\mathrm{Mg}$ alloy rolling schedules and control of the rolling process, and can also be easily extended to other types of $\mathrm{Mg}$ alloy hot rolling mill. Accurate force prediction is an important factor in optimizing the rolling conditions and is critical for a good product shape.

\section{References}

BAGHERIPOOR, M. and BISADI, H. 2013. Application of artificial neural networks for the prediction of roll force and roll torque in hot strip rolling process. Applied Mathematical Modelling, vol. 37, no. 7. pp. 4593-4607.

Chol, S.H., Kim, D.H., Lee, H.W., Seong, B.S., Piao, K., and Wagoner, R. 2009. Evolution of the deformation texture and yield locus shape in an AZ31 Mg alloy sheet under uniaxial loading. Materials Science and Engineering $A$, vol. 526. pp. 38-39.

Chol, S.H., Shin, E.J., and Seong, B.S. 2007. Simulation of deformation twins and deformation texture in an AZ31 Mg alloy under uniaxial compression. Acta Materialia, vol. 55. pp. 4181-4192.

Esmaizadeh, M. and Aghaie-Khafri, M. 2012. Finite element and artificial neural network analysis of ECAP. Computational Materials Science, vol. 63. pp. 127-133

FReSHWATER, I.J. 1996. Simplified theories of flat rolling - I: the calculation of roll pressure, roll force and roll torque. International Journal of Mechanical Sciences, vol. 38. pp. 633-648.

Gao, H., Ramalingam, S.C., Barber, G.C., and Chen, G. 2002. Analysis of asymmetrical cold rolling with varying coefficients of friction. Journal of Materials Processing Technology, vol. 124. pp. 178-182.

Hagan, M.T. and MenhaJ, M. 1994. Training feedforward networks with the Marquardt algorithm. IEEE Transactions on Neural Networks, vol. 5, no. 6. pp. 989-993.

HAN, F., Mo, J.H., QI, H.W., Long, R.F., CuI, X.H., and Li, Z.W. 2013. Springback prediction for incremental sheet forming based on FEM-PSONN. Transactions of Nonferrous Metals Society of China, vol. 23, no. 4. pp. 1061-1071.

HosoKAwa, H., CHino, Y., and Sнiмојіма, K. 2003. Mechanical properties and blow forming of rolled AZ31 Mg alloy sheet. Materials Transactions, vol. 44, no. 4. pp. 484-489.

KANG, S.H., LEE, Y.S., and LEE, J.H. 2008. Effect of grain refinement of magnesium alloy AZ31 by severe plastic deformation on material characteristics. Journal of Materials Processing Technology, vol. 201. pp. 436-440.

Kazan, R., Firat, M., and Tiryaki, A.E. 1994. Prediction of springback in wipebending process of sheet metal using neural network, Materials and Design, vol. 30. pp. 418-423.

KIM, D.J. and КІм, B.M. 2000. Application of neural network and FEM for metal forming processes. International Journal of Machine Tools and Manufacture, vol. 40. pp. 911-925.
KobaYASH, S., OH, S.I., and ALTAN, T. 1989. Metal Forming and the FiniteElement Method, Oxford University Press, New York.

LeE, J.B., Konno, T.H., and Jenog, H.G. 2010. Effect of differential speed rolling on anisotropy of mechanical properties and texture evolution of AZ31 Mg alloys. Journal of Alloys and Compounds, vol. 499, no. 2. pp. 273-277.

LI, N.L., HuAnG, G.J., XIN, R.L., and Liu, Q. 2013. Effect of initial texture on dynamic recrystallization and deformation mechanisms in AZ31 Mg alloy extruded at 573K. Materials Science and Engineering A, vol. 569, no. 1. pp. 18-26.

MoRDIKE, B.L. and EвERT, T. 2001. Magnesium, properties - applications potential. Materials Science and Engineering A, vol. 302. pp. 37-45.

Satto, Y., Utsunomiya, H., Tsuj, N., and SAKal, T. 1999. Novel ultra-high straining process for bulk materials development of the accumulative rollbonding (ARB) process. Acta Materialia, vol. 47, no. 2. pp. 579-583.

Shabani, M.O. and MAZAhERY, A. 2011. The ANN application in FEM modeling of mechanical properties of Al-Si alloy. Applied Mathematical Modelling, vol. 35, no. 12. pp. 5707-5713.

ShabAn, M.O., MAZAherY, A., RAhimipour, M.R., and RAZAVI, M. 2012. FEM and ANN investigation of A356 composites reinforced with B4C particulates. Journal of King Saud University - Engineering Sciences, vol. 24, no. 2. pp. 107-113.

Shahani, A.R., Setayeshi, S., Nodamaie, S.A., Asadi, M.A., and Rezaie S. 2009. Prediction of influence parameters on the hot rolling process using finite element method and neural network. Journal of Materials Processing Technology, vol. 209, no. 5. pp. 1920-1935.

Sun, J.N., Huang, H.G., Du, F.S., and LI, X.T. 2009. Nonlinear finite element analysis of thin strip temper rolling process. Journal of Iron and Steel Research, vol. 16, no. 4. pp. 27-32.

Sun, J.N., XuE, T., and Guo, Z.Y. 2013. Online calculation model of rolling force for Mg alloy rolling process. Advanced Materials Research, vol. 753-755. pp. 245-248.

Thirumurugan, M., Kumaran, S., Suwas, S., and SRinivasa Rao, T. 2011. Effect of rolling temperature and reduction in thickness on microstructure and mechanical properties of ZM21 magnesium alloy and its subsequent annealing treatment. Materials Science and Engineering $A$, vol. 528, no. 29. pp. 8460-8468.

Umbrello, D., Ambrogio, G., Filice, L., and Shivpuri, R. 2008. A hybrid finite element method-artificial neural network approach for predicting residual stresses and the optimal cutting conditions during hard turning of AISI 52100 bearing steel. Materials and Design, vol. 29, no. 4. pp. 873-883.

ZHANG, D.F., FANG, L., LIU, G.P., and DAI, Q.W. 2010. Research progress in rolling technology and process for magnesium alloy sheets. Ordnance Material Science and Engineering, vol. 33, no. 5. pp. 96-101. 